\title{
The British Mental Health Survey Programme: achievements and latest findings
}

\author{
Rachel Jenkins $\cdot$ Howard Meltzer $\cdot$ Paul Bebbington • \\ Traolach Brugha $\cdot$ Michael Farrell $\cdot$ Sally McManus • \\ Nicola Singleton
}

Published online: 20 August 2009

(C) Springer-Verlag 2009

\section{Introduction}

The British National Psychiatric Morbidity Survey Programme (http://www.mentalhealthsurveys.co.uk/) started in 1993, and it seems timely now, with the publication of the most recent survey [39], to take stock of its impact on our understanding of mental disorders and of what the next steps should be.

\author{
R. Jenkins $(\square) \cdot$ M. Farrell \\ Institute of Psychiatry, Kings College London, \\ 16 De Crespigny Park, London SE5 8AF, UK \\ e-mail: Rachel.Jenkins@kcl.ac.uk \\ M. Farrell \\ e-mail: michael.farrell@kcl.ac.uk \\ H. Meltzer · T. Brugha \\ Department of Health Sciences, University of Leicester, \\ 22-28 Princess Road West, Leicester LE1, UK \\ H. Meltzer \\ e-mail: hm74@leicester.ac.uk \\ T. Brugha \\ e-mail: tsb@le.ac.uk \\ P. Bebbington \\ Department of Mental Health Sciences, \\ University College London, 2nd Floor, Charles Bell House, \\ 67-73 Riding House Street, London W1W 7EJ, UK \\ e-mail: P.Bebbington@ucl.ac.uk

\section{S. McManus} \\ National Centre for Social Research, \\ 35 Northampton Square, London EC1V, UK \\ e-mail: Sally.McManus@natcen.ac.uk

\section{N. Singleton} \\ UK Drug Policy Commission, Kings Place, \\ 90 York Way, London N1, UK \\ e-mail: NSingleton@ukdpc.org.uk
}

The survey programme was designed to improve knowledge and understanding of mental illness, its causes and consequences, in order to inform governmental objectives for mental health [18]. These comprised prevention, treatment and rehabilitation of mental disorders; improvement of quality of life; prevention of mortality; provision of services and interventions; mental health promotion; tackling fear, ignorance and stigma around mental illness; and continued research into the causes, consequences and care of specific mental disorders, together with their contribution to social exclusion. The survey programme has provided a key source of continuous information to government, commissioners and researchers. Most recently it has informed the Foresight Report on Mental Capital and Wellbeing (www.foresight.gov.uk, [8]).

\section{Strategy and methods}

The approach linked the survey methodology of the Office for National Statistics (ONS, formerly OPCS), and more recently, the National Centre for Social Research (NatCen), with the expertise of psychiatric epidemiologists in academic departments of psychiatry. There was additional input from policy advisors from various governmental departments.

A population-based approach was taken, with a series of surveys of particular groups and subgroups, based on a model of probability sampling. While our survey methods have evolved over time, the emphasis has been on using a core of similar instruments to allow comparison between different population subgroups and periods. For each target group, the survey has been designed to assess:

- The prevalence of specific mental disorders in the population, including levels of drug and alcohol misuse; 
Table 1 Components of the British mental health survey programme

\section{Baseline surveys}

Adults living in private households 1993

Residents of institutions catering

for people with mental

disorders 1994

Homeless people including

those sleeping rough 1994

Prisoners 1997

Children and adolescents 1998

Children and adolescents

looked after by local

authorities 2001

People providing informal care 2001

Meltzer et al. [40, 41]

Meltzer et al. [42]

Gill et al. [24]

Singleton et al. [48]

Meltzer et al. [43]

Meltzer et al. [45]

Singleton et al. [49]

Repeat surveys

Adults living in private

households 2000

Adults living in private households 2007

Children and adolescents 2004

Longitudinal surveys

Adults living in private

households 2002

Children and adolescents 2002

Singleton et al. [50]

McManus et al. [38]

Green et al. [27]

Singleton and Lewis [51]

Meltzer et al. [46]

- The prevalence of risk factors and associated disabilities (physical illness, financial strain, smoking, social disabilities, sickness absence);

- Service utilisation by people with mental disorders, covering specialist mental health services and general medical, local authority and non-statutory services;

- The degree to which health and social care needs are being met.

The programme comprised three types of survey: summarised in Table 1 and Fig. 1;

- An initial survey for each specified population to provide baseline data;

- A follow up survey of respondents from the baseline survey to monitor clinical and non-clinical outcomes;

- Repeat surveys after 5-7 years to assess the change in population prevalence rates.

Besides monitoring changes in prevalence rates, service use and unmet need, surveys with a longitudinal element provide us with unique opportunities to test aetiological hypotheses. However, there have been as yet no repeat or longitudinal surveys of prisoners, homeless people, carers or children looked after by local authorities.

The British adult survey programme has used the revised Clinical Interview Schedule (CIS-R) [36] administered by lay interviewers in a first phase interview to cover anxiety and depressive symptoms. CIS-R assessments are related to the last 7 days, and the instrument was chosen because this minimises recall bias: it is likely to be more accurate than lifetime and 12 month assessments. A second phase involved clinical assessments of a subset of respondents using SCAN, and SCID-II to cover psychosis, personality disorders and other conditions requiring clinical assessment $[23,56]$. The survey also allows dimensional analyses, examples of which include those of [39] on disability and of [34] on the distribution of psychotic symptoms based on the Psychosis Screening Questionnaire (PSQ) [1].

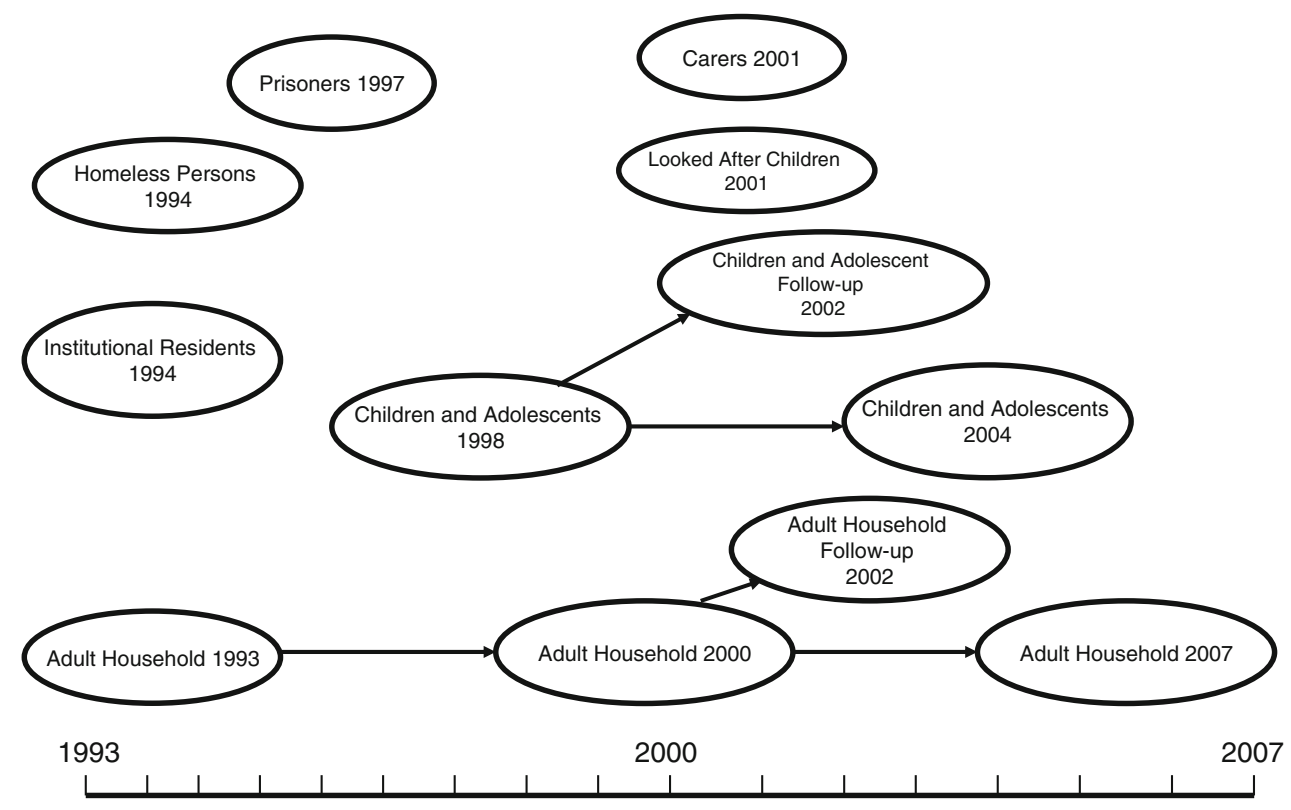

Fig. 1 The British psychiatric morbidity survey programme 
In the children's surveys, the initial assessment involved the Strengths and Difficulties Questionnaire (SDQ) [25] and the Development and Well-Being Assessment (DAWBA) [26] followed by a clinical assessment of qualitative and quantitative data from three collateral sources.

Repeat surveys included an invariant core of questions to measure factors associated with disorders such as sociodemographic characteristics, activities of daily living [9, 37], recent stressful life events [10], social support networks [11] and the use of services and treatments.

\section{Achievements of the survey programme and latest findings}

The surveys have delineated the scale of psychiatric morbidity and of accompanying disability in the general population and particular subgroups [3, 29-31]. They have also enhanced our understanding of relatively under-investigated conditions such as developmental disorders [27].

The 2007 survey introduced for the first time screening for certain conditions as a way of profiling the associated traits in the population [38]. This included the first assessments of the adult population for features of post traumatic stress disorder (PTSD), attention deficit hyperactivity disorder (ADHD), eating disorders, and problematic and pathological gambling.

A third of adults reported having experienced a traumatic event of some kind after the age of 16, although overall only $3.0 \%$ of people screened positive for current PTSD; rates declined with increasing age.

A total of $8.2 \%$ of adults screened positive for ADHD, as indicated by a score of four and above on a 6-item selfreport scale; $2.3 \%$ reported five characteristics and $0.6 \%$ all six characteristics. Only a fifth of screen positive participants were receiving psychiatric treatment of any kind.

A total of $6.4 \%$ of adults screened positive for an eating disorder, of whom a fifth were receiving treatment, and $1.6 \%$ of adults screened positive and reported that the eating problems had a significant negative impact on their life.

While two-thirds of adults had spent money on gambling in the last year, only $3.2 \%$ met one or more of the criteria for problem gambling, $0.7 \%$ met three or more criteria and $0.3 \%$ met the threshold of five or more criteria taken to indicate pathological gambling. A quarter of the latter were receiving some kind of treatment for a mental or emotional problem.

Other conditions, including common mental disorder, psychosis, alcohol and drug abuse and personality disorder, have been assessed throughout the survey programme, allowing comparisons over time. Prevalences can be traced for England across all three surveys. Between 1993 and 2000 there was a significant increase in the population aged
16-64 in the prevalence of CMD, from $15.5 \%$ to $17.5 \%$, but no further increase by 2007 (17.6\%).

The prevalence of alcohol dependence was $5.9 \%$ in 2007, having fallen somewhat in men since 2000. The prevalence of hazardous drinking among 16-74 year olds was also reduced, from $28.1 \%$ in 2000 down to $25.5 \%$ in 2007. The prevalence of drug dependence was $3.4 \%$ in 2007, similar to 2000, but still higher than in 1993 .

Suicidal thoughts at some point in people's lives are relatively common: in the 2007 survey $16.7 \%$ had thought about committing suicide, $5.6 \%$ had attempted suicide and $4.9 \%$ had harmed themselves without suicidal intent. In England, the proportion of women reporting suicidal thoughts in the last year, and of people reporting self harm, increased between 2000 and 2007.

The overall prevalence of probable psychosis was $0.5 \%$ (unchanged from previous years).

Antisocial personality disorder was assessed in the 2000 and 2007 surveys. In 2007, it was identified in $0.3 \%$ of adults $(0.6 \%$ men, $0.1 \%$ women $)$, mostly in the younger age groups, while borderline personality disorder was identified in $0.4 \%$ of adults ( $0.3 \%$ men, $0.6 \%$ women). Rates were similar in 2000. Comorbidity was common, especially between antisocial personality disorder and psychosis.

In addition, the survey programme has increased our understanding of the links between mental illness and substance abuse, including nicotine (e.g. [17, 19-21]); physical illness and PD, [47]; mental disorders and PD (e.g. [54]); and mental disorder and violence (e.g. [14, 15]).

The surveys also examined the extent to which people with disorders accessed services and treatment [4, 5, 13, $22,53]$. Only a quarter of people with CMD were receiving some kind of treatment in 2007, unchanged from 2000. Strikingly, the use of psychotropic medication for CMD doubled between 1993 and 2000, although use of talking therapies did not significantly increase [13]. Few people with drug and alcohol misuse were receiving treatment [22]. In contrast, most people with psychosis were in touch with health and social care, the majority receiving some form of treatment (85\% in 2000 and $80 \%$ in 2007).

Secondary analyses of these datasets have greatly enriched our understanding of risk factors for mental disorders. Our investigations have covered such topics as age and gender differences, lone mothers, parenting, debt and the role of primary support groups $[2,12,16,33,52,55]$. Other studies have established the links between victimisation experiences and psychosis [6], and the factors leading to suicidal behaviour [7, 28, 32, 44].

The factors associated with higher rates of mental disorder among adults include sociodemographic factors (being female, aged between 35 and 54, social class V, tenants of Local Authorities and Housing Associations); 
characteristics of the family (separation or divorce, living as a one person family unit, or as a lone parent) and personal characteristics (a predicted verbal IQ of 70-85, impaired personal functioning, no formal educational qualification, one or more physical complaints).

New episodes of psychiatric illness were twice as common in adults living in rented accommodation, and three times as common in women reporting six or more stressful life events. Onsets were also more common in men who were unemployed, and in men with low income.

People with common mental disorders are more likely to have experienced several stressful life events in the last 6 months, and to have smaller social networks than those with no disorder. These features are even more marked in people in prison, homeless people and informal carers than in the population as a whole. Life events are clearly important risk factors for common mental disorders. The strongest associations between CMD and life events related to recent threats to health, recent interpersonal problems and lifetime stressors (including sexual abuse and expulsion from school). The strength of association between recent life events and CMD increased steadily up to the 4554 age group, declining thereafter. In the 65-74 year age range, CMD was significantly associated with lifetime stressors, but not with recent life events. The lifetime stressors included bullying, sexual abuse, running away from home and institutional care in childhood [35].

Attributes associated with higher rates of mental disorder among children include characteristics of the child (physical health problems and having special educational needs); characteristics of the family (lone parenthood, reconstituted families, poor educational levels, lack of employment and low income); family functioning characteristics (psychological distress among mothers and family discord); stressful life events (separation of parents, parents in trouble with the police) and neighbourhood characteristics (deprivation and lack of social cohesion).

\section{Conclusions}

The British National Mental Health Surveys have had considerable impact on policy, and on cross-governmental preparations for the future delivery of health, education, social welfare and criminal justice (www.foresight.gov.uk) [8]. Local services, public health advisors, economists and national governments depend on such information. We feel the approaches and methods developed and used in this programme of surveys have provided a cost-effective balance of information: on dimensions and categories, determinants and consequences, health and social service use and other behaviours. Future surveys should incorporate interdisciplinary components, for example by including biological sampling. Repeat surveys and follow-up surveys greatly add to the potential of the survey programme, and should in future become a standard requirement.

The 2007 survey report can be found at: www.ic.nhs.uk/pubs/psychiatricmorbidity07

Acknowledgments The programme has been supported by the Department of Health, the Scottish Health Executive (formerly the Scottish Office), the Welsh Assembly Government (formerly the Welsh Office) and the NHS Information Centre for Health and Social Care.

\section{References}

1. Bebbington PE, Nayani T (1995) The psychosis screening questionnaire. Int J Methods Psychiatr Res 5:11-20

2. Bebbington PE, Dunn G, Jenkins R, Lewis G, Brugha T, Farrell $M$, Meltzer H (1998) The influence of age and sex on the prevalence of depressive conditions: report from the National survey of psychiatric morbidity. Psychol Med 28:9-19

3. Bebbington P, Brugha T, Meltzer M, Farrell M, Ceresa C, Jenkins R, Lewis G (2000) Psychiatric disorder and dysfunction in the UK National survey of psychiatric morbidity. Soc Psychiatry Psychiatr Epidemiol 35:191-197

4. Bebbington P, Brugha T, Meltzer M, Farrell M, Ceresa C, Jenkins R, Lewis G (2000) Neurotic disorders and the receipt of psychiatric treatment. Psychol Med 30:1369-1376

5. Bebbington PE, Meltzer H, Brugha T, Farrell M, Jenkins R, Ceresa C, Lewis G (2000) Unequal access and unmet need: neurotic disorders and the use of primary care services. Psychol Med 30:1359-1367

6. Bebbington PE, Bhugra D, Brugha T, Farrell M, Lewis G, Meltzer H, Jenkins R, Lewis G, Meltzer H (2004) Psychosis, victimisation and childhood disadvantage: evidence from the second British National survey of psychiatric epidemiology. Br J Psychiatry 185:220-226

7. Bebbington PE, Cooper C, Minot S, Brugha TS, Jenkins R, Meltzer H, Dennis M (2009) Suicide attempts, gender and sexual abuse: data from the British psychiatric morbidity survey 2000. Am J Psychiatry (in press)

8. Beddington J, Cooper CL, Field J, Goswami U, Huppert FA, Jenkins R, Jones HS, Kirkwood TBL, Sahakkian BJ, Thomas SM (2008) The mental wealth of nations. Nature 455:1057-1060

9. Brewin C, Wing J (1989) Needs for care assessment. MRC social psychiatry unit. Institute of Psychiatry, London

10. Brugha T, Bebbington P, Tennant C, Hurry J (1985) The list of threatening experiences: a subset of 12 life event categories with considerable long-term contextual threat. Psychol Med 15: 189-194

11. Brugha TS, Sturt E, MacCarthy B, Potter J, Wykes T, Bebbington PE (1987) The interview measure of social relationships: the description and evaluation of a survey instrument for assessing personal social resources. Soc Psychol 22:123-128

12. Brugha TS, Morgan Z, Bebbington P, Jenkins R, Lewis G, Farrell M, Meltzer H (2003) Social support networks and type of neurotic symptom among adults in British households. Psychol Med 33:307-318

13. Brugha TS, Bebbington PE, Singleton N, Melzer D, Jenkins R, Lewis G, Farrell M, Bhugra D, Lee A, Meltzer H (2004) Trends in service use and treatment for mental disorders in adults throughout Great Britain. Br J Psychiatry 185:378-384

14. Coid J, Yang M, Roberts A, Ullrich S, Moran P, Bebbington P, Brugha T, Jenkins R, Farrell M, Lewis G, Singleton N (2006) 
Violence and psychiatric morbidity in a national household population-a report from the British household survey. Am J Epidemiol 164:1199-1208

15. Coid J, Yang M, Roberts A, Ullrich S, Moran P, Bebbington P, Brugha T, Jenkins R, Farrell M, Lewis G, Singleton N (2006) Violence and psychiatric morbidity in the national household population of Britain: public health implications. Br J Psychiatry 189:12-19

16. Cooper C, Bebbington PE, Meltzer H, Bhugra D, Brugha T, Jenkins R, Farrell M, King M (2008) Depression and common mental disorders in lone parents: results of the 2000 National psychiatric morbidity survey. Psychol Med 38:335-342

17. Coulthard M, Farrell M, Singleton N, Meltzer H (2002) Tobacco, alcohol and drug use and mental health. TSO, London

18. Department of Health (1993) The health of the Nation: key area handbook on mental illness. Department of Health, London

19. Farrell M, Howes S, Taylor C, Lewis G, Jenkins R, Bebbington P, Jarvis M, Brugha T, Gill B, Meltzer H (1998) Substance misuse and psychiatric comorbidity: an overview of the OPCS surveys. Br J Addict 23:909-918

20. Farrell M, Howes S, Bebbington P, Brugha T, Jenkins R, Lewis G, Marsden J, Taylor C, Meltzer H (2002) Nicotine, alcohol and drug dependence and psychiatric morbidity results of a national household survey. Br J Psychiatry 179:432-437

21. Farrell M, Boys A, Bebbington P, Brugha T, Coid J, Jenkins R, Lewis G, Meltzer H, Marsden J, Singleton N, Taylor C (2002) Psychosis and drug dependence: results from a national survey of prisoners. Br J Psychiatry 181:1-6

22. Farrell M, Boys A, Singleton N, Meltzer H, Brugha T, Bebbington P, Brugha T, Jenkins R, Coid J, Lewis G, Marsden J (2006) Predictors of mental health service utilisation in the 12 months before imprisonment: analysis of results from a national prisons survey. Aust N Z J Psychiatry 40:548-553

23. First MB, Gibbon M, Spitzer RL, William JBW, Benjamin L (1997) Structured clinical interview for DSM - IV Axis II personality disorders. American Psychiatric Press, Washington

24. Gill B, Meltzer H, Hinds K, Petticrew M (1996) In: Office for National Statistics Social Survey Division (ed) OPCS surveys of psychiatric morbidity in Great Britain. Report 7: psychiatric morbidity among homeless people. 7:238. HMSO, London

25. Goodman R, Ford T, Richards H, Gatward R, Meltzer H (2000) The development and well-being assessment: description and initial validation of an integrated assessment of child and adolescent psychopathology. J Child Psychol Psychiatry 41:645-655

26. Goodman R, Ford T, Simmons H, Gatward R, Meltzer H (2000) Using the Strengths and Difficulties Questionnaire (SDQ) to screen for child psychiatric disorders in a community sample. $\mathrm{Br}$ J Psychiatry 177:534-539

27. Green H, McGinnity A, Meltzer H, Ford T, Goodman R (2005) Mental health of children and young people in Great Britian (2004). Palgrave McMillan, Hampshire

28. Gunnell D, Harbord R, Singleton N, Jenkins R, Lewis G (2004) Factors affecting the development and amelioration of suicidal thoughts in a general population sample in England: a cohort study. Br J Psychiatry 185:385-393

29. Jenkins R (2001) Making psychiatric epidemiology useful: the contribution of epidemiology to mental health policy. Acta Psych Scand 103:2-14

30. Jenkins R, Lewis G, Bebbington P, Brugha T, Farrell M, Gill B, Meltzer H, Petticrew M (1997) The National psychiatric morbidity surveys of Great Britain strategy and methods. Psychol Med 27:765-774

31. Jenkins R, Bebbington $P$, Brugha T, Farrell M, Lewis G, Meltzer H (1998) British psychiatric morbidity survey. Br J Psychiatry 173:4-7

32. Jenkins R, Brugha D, Meltzer H, Singleton N, Bebbington $P$, Brugha T, Coid J, Farrell M, Lewis G, Paton J (2005) Psychiatric and social aspects of suicidal behaviour in prisons. Psychol Med $35: 257-269$

33. Jenkin R, Bhugra D, Bebbington PE, Brugha T, Farrell M, Coid J, Fryers T, Weich S, Singleton N, Meltzer H (2008) Debt, income and mental disorder in the general population. Psychol Med 38:1485-1493

34. Johns LC, Cannon M, Singleton N, Murray RM, Farrell M, Brugha T, Bebbington P, Jenkins R, Meltzer H (2004) The prevalence and correlates of self-reported psychotic symptoms in the British population. Br J Psychiatry 185:298-305

35. Jordanova V, Stewart R, Goldberg D, Bebbington PE, Brugha T, Singleton N, Lindesay JEB, Jenkins R, Prince M, Meltzer H (2007) Age variation in life events and their relationship with common mental disorders in a national survey population. Soc Psychiatry Psychiatr Epidemiol 42:611-616

36. Lewis G, Pelosi AJ, Araya R, Dunn G (1992) Measuring psychiatric disorder in the community; a standardised assessment for use by lay interviewers. Psychol Med 22:465-486

37. Martin J, Meltzer H, Elliot D (1988) The OPCS Surveys of disability in Great Britain, Report 1, the prevalence of disability among adults. HMSO, London

38. McManus S, Meltzer $\mathrm{H}$, Brugha $\mathrm{T}$, Bebbington $\mathrm{P}$, Jenkins $\mathrm{R}$ (2009) Adult psychiatric morbidity in England, 2007: results of a household survey. National Centre for Social Research, London

39. Melzer D, Fryers T, Jenkins R, Brugha T, McWilliams B (2003) Social position and the common mental disorders with disability: estimates from the National psychiatric survey of Great Britain. Soc Psychiatry Psychiatr Epidemiol 38:238-243

40. Meltzer H, Gill B, Petticrew M, Hinds K (1995) OPCS surveys of psychiatric morbidity in Great Britain, Report 1: the prevalence of psychiatric morbidity among adults living in private households. HMSO, London

41. Meltzer H, Gill B, Petticrew M, Hinds K (1995) OPCS surveys of psychiatric morbidity in Great Britain, Report 3: economic activity and social functioning of adults with psychiatric disorders. HMSO, London

42. Meltzer H, Gill B, Hinds K, Petticrew M (1996) OPCS surveys of psychiatric morbidity in Great Britain, Report 4: the prevalence of psychiatric morbidity among adults living in institutions. HMSO, London

43. Meltzer H, Gatward R, Goodman R, Ford T (2000) Mental health of children and adolescents in Great Britain. TSO, London

44. Meltzer H, Lader D, Corbin C, Singleton S, Jenkins R, Brugha T (2002) Non-fatal suicidal behaviour among adults aged 16-74 in Great Britain. TSO, London

45. Meltzer H, Gatward R, Corbin T, Goodman R, Ford T (2003) The mental health of young people looked after by local authorities in England. TSO, London

46. Meltzer H, Gatward R, Corbin T, Goodman R, Ford T (2003) Persistence, onset, risk factors and outcomes of childhood mental disorders. TSO, London

47. Moran P, Stewart R, Brugha T, Bebbington P, Bhugra D, Jenkins R, Coid JW (2007) Personality disorder and cardiovascular disease: results from a National household survey. J Clin Psychiatry 68:69-74

48. Singleton N, Meltzer H, Gatward R (1998) Psychiatric morbidity among prisoners in England and Wales. TSO, London

49. Singleton N, Maung NA, Cowie A, Sparks J, Bumpsteead R, Meltzer H (2002) Mental health of carers. TSO, London

50. Singleton N, Bumpstead R, O’Brien M, Lee A, Meltzer H (2001) Psychiatric morbidity among adults living in private households 2000. TSO, London

51. Singleton N, Lewis G (2003) Better or worse: a longitudinal study of the mental health of adults living in private households in Great Britain. TSO, London

52. Targosz S, Bebbington P, Lewis G, Brugha T, Jenkins R, Farrell M, Meltzer H (2003) Lone mothers, social exclusion and depression. Psychol Med 33:715-722 
53. Torres AR, Prince MJ, Bebbington PE, Bhugra D, Brugha TS, Farrell M, Jenkins R, Lewis G, Meltzer H, Singleton N (2006) Obsessive-compulsive disorder: prevalence, comorbidity, impact and help-seeking in the UK National psychiatric morbidity survey of 2000. Am J Psychiatry 163:1978-1985

54. Torres AR, Moran P, Bebbington P, Brugha T, Bhugra D, Coid J, Farrell M, Jenkins R, Lewis G, Meltzer H, Prince M (2006) Obsessive -compulsive disorder and personality disorder. Evidence from the British national survey of psychiatric morbidity 2000. Soc Psychiatry Psychiatr Epidemiol 41:862-867
55. Vostanis P, Brugha T, Goodman R, Graves A, Jenkins R, Meltzer H (2006) Relationship between parental psychopathology, parenting strategies and child mental health: findings from the GB national study. Soc Psychiatry Psychiatr Epidemiol 41:509-514

56. World Health Organisation, Division of Mental Health (1999) SCAN Schedules for clinical assessment in neuropsychiatry Version 2.1. World Health Organisation, Geneva 